\title{
Covariability between the Baiu Precipitation and Tropical Cyclone Activity through Large-Scale Atmospheric Circulations
}

\author{
Tsuyoshi YAMAURA \\ Graduate School of Science and Technology, Kumamoto University, Kumamoto, Japan \\ and
}

Tomohiko TOMITA

Graduate School of Science and Technology, Kumamoto University, Kumamoto, Japan Research Institute for Global Change, Japan Agency for Marine-Earth Science and Technology, Yokohama, Japan

(Manuscript received 6 June 2011, in final form 5 April 2012)

\begin{abstract}
Interannual variations of both the Baiu precipitation and tropical cyclone (TC) activity in the western North Pacific (WNP) are controlled by large-scale atmospheric circulations associated with the El Niño/Southern oscillation (ENSO) and the tropospheric biennial oscillation (TBO) of the Asian monsoon. This work examines covariability between the Baiu precipitation and the TC activity in the WNP through the ENSO and the TBO.

In years when sea surface temperature anomalies (SSTAs) are negative in the eastern tropical Pacific with respect to the ENSO, the number of TCs increases near the Philippines in the Baiu season, June and July. On the other hand, in years of negative SSTAs in the eastern tropical Pacific related to the TBO, the strength of TCs is enhanced to the southeast of Japan. Each of these two TC activities enhances a cyclonic circulation there, which shifts the axis of monsoon southwesterlies and contributes to form the peculiar Baiu precipitation anomalies. These modifications are, however, dependent on the phase of the ENSO and the TBO. In years of positive SSTAs in the eastern tropical Pacific, the anomalous TC activity is small and sometimes has opposing effects on the atmospheric circulations of the ENSO and TBO. Thus, the covariability is strong between the Baiu precipitation and TC activity in the WNP in the specific phase of the ENSO and the TBO, although both covary in large-scale atmospheric circulations.
\end{abstract}

\section{Introduction}

The Baiu (in Japanese; Mei-yu in Chinese, and Changma in Korean) front is a large-scale precipitation system appearing in early boreal summer in East Asia (EA)-the western North Pacific (WNP) sector, which primarily controls summertime precipitation across the

Corresponding author and present affiliation: Tsuyoshi Yamaura, RIKEN Advanced Institute for Computational Science, 7-1-26, Minatojima-minami-machi, Chuo-ku, Kobe, Hyogo, 650-0047, Japan.

E-mail: info@spherewind.com

(C)2012, Meteorological Society of Japan region. To manage water resources and mitigate the impacts of natural disasters associated with the Baiu precipitation, countries in EA need to improve their prediction scheme for the Baiu frontal activity more comprehensively. Many studies have examined the physical mechanisms of the interannual variability in the Baiu frontal activity (e.g., Tanaka 1997; Kawamura and Murakami 1998; Chang et al. 2000a, 2000b; Tomita et al. 2004; Yamaura and Tomita 2011).

Several studies have investigated correlation between the Baiu precipitation and El Niño/Southern oscillation (ENSO; Rasmusson and Carpenter 1982), which is established while the ENSO, with its periodicity of 3 to 4 years, affects the global climate. Tanaka 
(1997) showed that in onset years of El Niño (La Niña), the Baiu precipitation tended to increase (decrease). Tomita et al. (2004) and Yamaura and Tomita (2011) examined more detailed spatial patterns of the Baiu precipitation anomalies formed by the PacificEast Asian (PEA) teleconnection of the ENSO (Wang et al. 2000).

The tropospheric biennial oscillation (TBO) of the Asian monsoon (Meehl 1987, 1993, 1997) also modifies the interannual variations in Baiu precipitation. Although the sea surface temperature anomalies (SSTAs) associated with the TBO are similar to those of the ENSO (e.g., Chang and Li 2000; Meehl and Arblaster 2002; Kawamura et al. 2003; Meehl et al. 2003; Li et al. 2006), they have a different spatial phase which is shifted by approximately $\pi / 2$ in the WNP, thus enabling the specific PEA-like teleconnection (Tomita et al. 2004). Anomalous meridional circulations associated with the SSTAs alter precipitation, particularly in the western part of the Baiu front between $110^{\circ}-140^{\circ} \mathrm{E}$ (Yamaura and Tomita 2011). Shen and Lau (1995) reported that interannual variation in precipitation over China, relating to the western Baiu precipitation, displayed a strong biennial tendency caused by an anomalous anticyclone near the Philippines and the modification of water vapor flow.

Many researchers have investigated the relationship between the ENSO and TC activity in the WNP (e.g., Chan 2000, 2007; Wang and Chan 2002; Camargo and Sobel 2005). For instance, Chan (2000) and Camargo and Sobel (2005) revealed that in the boreal fall when an El Niño event developed, the number of TCs tended to decrease in the South China Sea, but increase in the eastern part of the western tropical Pacific $\left(0^{\circ}-20^{\circ} \mathrm{N}\right.$, $\left.140^{\circ} \mathrm{E}-180^{\circ}\right)$. Wang and Chan (2002) also noted that TCs in the WNP tend to occur at lower latitudes, move farther northward, and have longer lifetime during an El Niño event than at the other times. In the years following an El Niño event, TC activity is suppressed from January to July. With a similar distribution of SSTAs and anomalous atmospheric circulations, the TBO probably alters TC activity in the WNP, although this still remains to be confirmed.

The TCs in the EA-WNP sector have potential for changing the strength and spatial distribution of the Baiu precipitation as they approach the Baiu front. However, the TCs may not influence the total Baiu precipitation because the number of TC geneses is not large in the WNP during June-July (6 TCs on average) and therefore the effects are restricted in time and space. This work examines this covariation in more detail, that is, if event-like TCs in the WNP signifi-

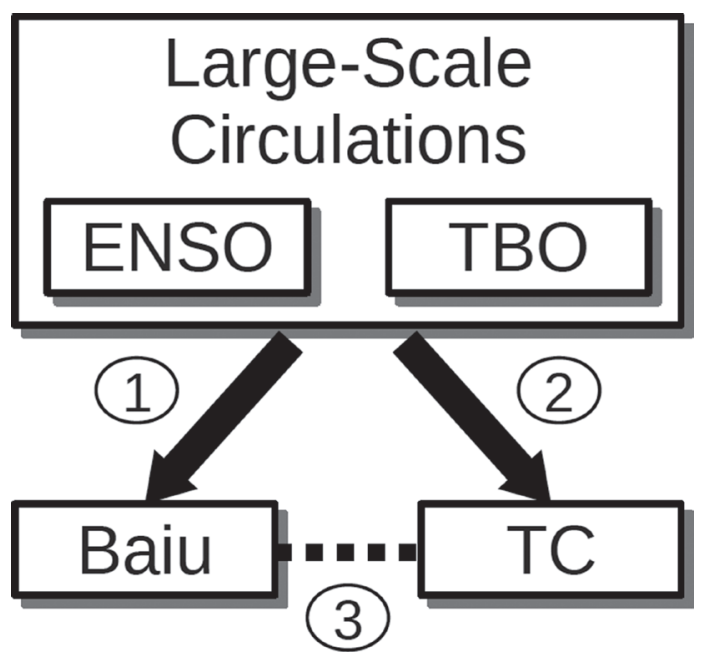

Fig. 1. Schematic flow diagram showing the relationship among the Baiu precipitation, TC activity, and large-scale atmospheric circulations associated with the ENSO and the TBO. Covariability between the Baiu precipitation and TC activity illustrated by a dotted line is mainly examined in this work. Numbers in a circle indicate the flow of discussions in this work.

cantly modify the amount and distribution of the Baiu precipitation in a year by diagnosing covariability between the TC activity and the Baiu precipitation from the large-scale point of view. The interannual tendency is particularly investigated in large-scale atmospheric variations associated with the ENSO and the TBO.

The aim of this work is to understand the interannual variability in Baiu precipitation more comprehensively. The specific targets are summarized in Fig. 1 , which illustrates the flows diagnosed in this work. We primarily re-examined whether large-scale atmospheric circulations associated with the ENSO and the TBO control the interannual variations of the Baiu precipitation. We then reveal how the ENSO and the TBO modify TC activity in the WNP during the Baiu season. Finally, we evaluated covariability between the Baiu precipitation and the TC activity in the WNP through the large-scale atmospheric circulations modified by the ENSO and the TBO.

The rest of this paper is structured as follows. Section 2 presents data and methodologies used in this work. Section 3 demonstrates how the ENSO and the TBO modify the Baiu precipitation on interannual time scales. Section 4 discusses the interannual variability of TC activity in the WNP with respect to the ENSO and the TBO. Section 5 examines how large-scale at- 
mospheric circulations modified by the ENSO and the TBO connect the Baiu precipitation anomalies and the anomalous TC activity in the WNP. Finally, a summary of this work and further discussions are given in Section 6.

\section{Data and methodology}

This work uses data from the following five datasets: (1) the Global Precipitation Climatology Project (GPCP) monthly data for precipitation rate, which are set on global grids with a $2.5^{\circ}$ interval (Adler et al. 2003); (2) the Japanese 25-year Reanalysis (JRA-25)/ Japan Meteorological Agency Climate Data Assimilation System (JCDAS) 6-hourly and monthly data for atmospheric parameters covering the globe with a spatial resolution of $1.25^{\circ}$ (Onogi et al. 2007); (3) the Hadley Centre Sea Ice and Sea Surface Temperature (HadISST) data edited by the United Kingdom Meteorological Office for monthly SST, which cover almost the entire globe with $1^{\circ}$ grids (Rayner et al. 2003); (4) daily data of global outgoing long-wave radiation (OLR) compiled by the National Oceanic and Atmospheric Administration (NOAA) with a $2.5^{\circ}$ grid interval (Liebmann and Smith 1996); and (5) 6-hourly data of TCs in the WNP $\left(100^{\circ} \mathrm{E}-180^{\circ}, 0^{\circ}-50^{\circ} \mathrm{N}\right)$ collected by the Joint Typhoon Warning Center (JTWC). This work uses the location and maximum wind speed of all TCs, which includes tropical depressions whose maximum wind speed is less than $17.2 \mathrm{~m} \mathrm{~s}^{-1}$. To diagnose atmospheric circulations associated with interannual variations in the Baiu precipitation, this work employs data collected during the Baiu season (June and July) for a time period from 1979 to 2008 (30 years).

In general, the existence of TCs has a large impact on daily mean atmospheric circulations. However, these impacts may be small when considering monthly mean atmospheric circulation because TCs occur infrequently and therefore their impacts are diluted over the longer time frame. To evaluate the effect of TCs in a region, we estimated the number of TCs (NTC) and the accumulated cyclone energy (ACE; Bell et al. 2000; Camargo and Sobel 2005). NTC is simply formulated as follows:

$$
N T C \equiv \sum_{\text {time area }} \sum_{\text {are }} N,
$$

where $N$ is the number of TCs in an area. ACE is a parameter related to the kinetic energy and is expressed as follows:

$$
\left.A C E \equiv \sum_{\text {time area }} \sum_{\max }\right)^{2},
$$

where $V_{\max }$ is the maximum wind speed of TCs. To ex- hibit the spatial distributions of NTC and ACE in the WNP $\left(100^{\circ} \mathrm{E}-180^{\circ}, 0^{\circ}-50^{\circ} \mathrm{N}\right)$, we estimated these two parameters for every $2.5^{\circ} \times 2.5^{\circ}$ grid cell. To determine the interannual variability of these parameters during the Baiu season, a temporal summation for June and July was calculated for every year from 1979 to 2008 (30 years) using the total number of observations made over the two months (244: four times daily over 61 days).

The empirical orthogonal function (EOF) analysis was conducted on the Baiu precipitation data to extract the dominant interannual variations. In addition, we applied the power spectral analysis to the time coefficients of the EOF modes to reveal significant periodicity. To estimate anomalies associated with each of the EOF modes, we calculated two 10-year means, one with positive and the other with negative time coefficients. The difference between these two means was termed the differential anomaly. The difference from the long-term (1979-2008; 30 years) mean was also calculated for the two 10-year means as a general anomaly.

\section{Interannual variations in the Baiu precipitation and the associated large-scale atmospheric cir- culations}

This section discusses how typical large-scale interannual variations, such as the ENSO and the TBO of the Asian monsoon, modulate the Baiu precipitation. Before discussing anomaly fields, we briefly describe the climatology of Baiu precipitation. Figure 2 shows the 30-year (1979-2008) mean precipitation rate, the standard deviation, and the vertically $(300-1000 \mathrm{hPa})$ integrated water vapor flux in the WNP for June to July. The vectors of vertically integrated water vapor flux represent lower atmospheric circulations because moisture tends to concentrate in the lower troposphere. During the Baiu season, a large-scale rain band, which identifies the Baiu front, extends northeastward from the southeastern part of China to the east of Japan. In this front, locally large precipitation rates $(>10 \mathrm{~mm}$ day $^{-1}$ ) are observed in and around Kyushu, Japan. The regions with large standard deviations (shaded) correspond to those areas with large means (contours). The monsoon westerlies that blow through the Bay of Bengal converge around the Philippines with the trades in the southwestern periphery of the North Pacific subtropical high. As a result, warm and moist air from the tropics steers northward, reaching Japan, Korea, and eastern China. It is conceivable that the Baiu front is a subsystem of the Asian summer monsoon which is located in the northernmost part. 


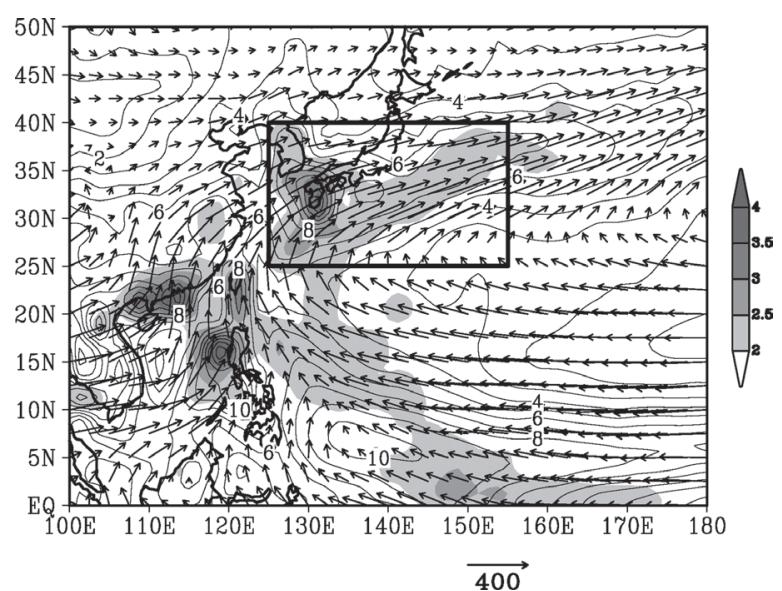

Fig. 2. Long-term (1979-2008; 30 years) mean precipitation rate $\left(\mathrm{mm}\right.$ day $^{-1}$; contour; GPCP), standard deviation ( $\mathrm{mm}$ day $^{-1}$; shading), and mean of vertically $(300-1000 \mathrm{hPa})$ integrated water vapor fluxes estimated from JRA-25/ JCDAS data $\left(\mathrm{kg} \mathrm{m}^{-1} \mathrm{~s}^{-1}\right.$; vector) for JuneJuly. The contour interval is $1.0 \mathrm{~mm} \mathrm{day}^{-1}$. The shading scale is shown at the right of the panel, and the vector scale is shown at the bottom. The rectangle $\left(25^{\circ}-40^{\circ} \mathrm{N}, 125^{\circ}-155^{\circ} \mathrm{E}\right)$ shows the region for $\mathrm{EOF}$ analysis.

To investigate the interannual variability of Baiu precipitation near Japan, we applied the EOF analysis to the precipitation rate data in an area where large standard deviations appeared on interannual time scales $\left(25^{\circ}-40^{\circ} \mathrm{N}, 125^{\circ}-155^{\circ} \mathrm{E}\right.$; the rectangle in Fig. 2). This approach may spatiotemporally expand the findings of Tomita et al. (2004). Additionally, Yamaura and Tomita (2011) employed the cluster analysis to extract dominant interannual variations in the Baiu precipitation for June. Those studies revealed that the effects of the ENSO were spatially orthogonal to those of the TBO, suggesting that the EOF analysis is useful in extracting the dominant interannual variations in the Baiu precipitation on large spatial scales.

Figure 3 demonstrates the eigenvector, normalized time coefficients, and power spectral density of the coefficients for the first EOF mode (EOF1) which explains $34.5 \%$ of the total variance. The eigenvector exhibits a remarkable monopole pattern with negative values centered to the south of Kyushu, Japan, although small positive values appear around the Korean Peninsula (Fig. 3a). This pattern indicates that the Baiu precipitation is suppressed to the south of Japan and is weakly enhanced around the Korean Peninsula in years
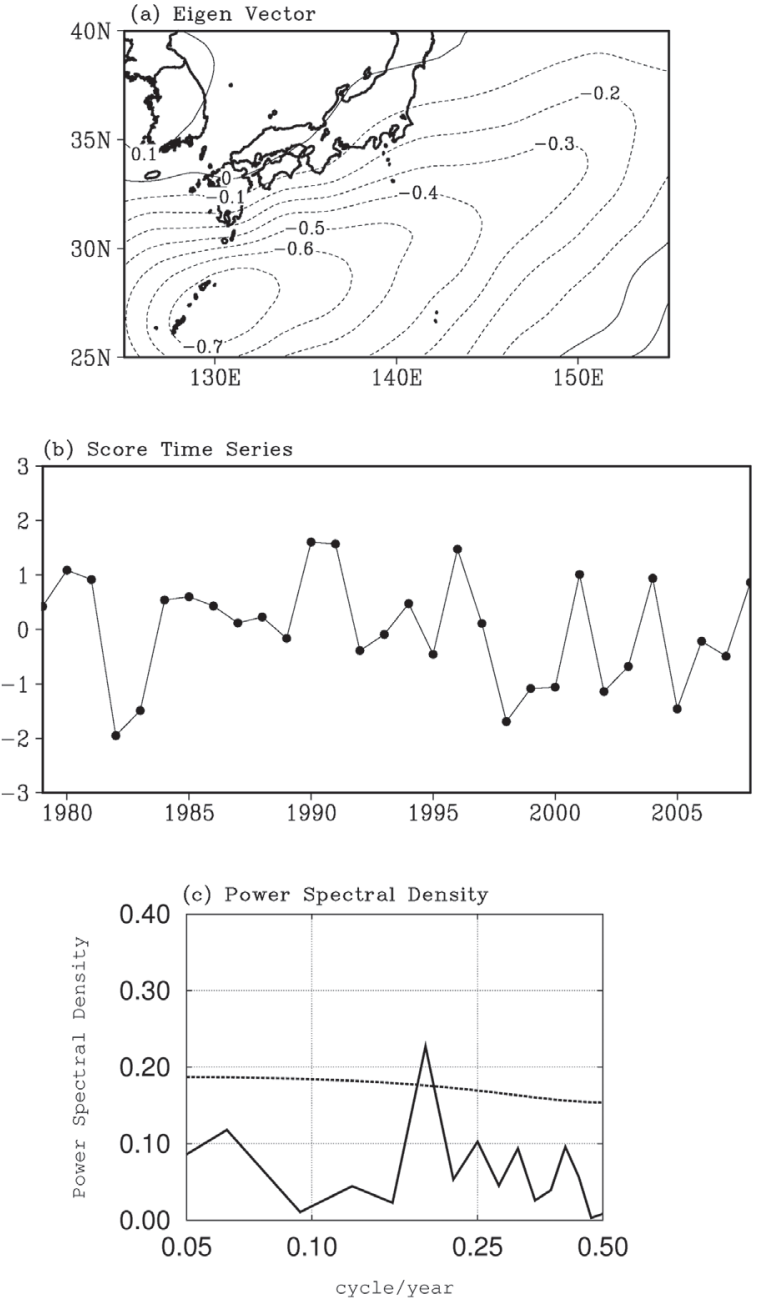

Fig. 3. The first mode of EOF analysis applied to the interannual variations in precipitation rate in June-July. The examined region $\left(25^{\circ}-40^{\circ} \mathrm{N}\right.$, $125^{\circ}-155^{\circ} \mathrm{E}$ ) is shown by the rectangle in Fig. 2 . The eigenvector is shown in (a), the normalized time coefficients are indicated in (b), and the power spectral density (PSD) of (b) is exhibited in (c) with the $95 \%$ significance (dotted line) estimated from the red noise spectrum based on a first-order auto-regression. The standard deviation for the normalization in (b) is imposed on the eigenvector in (a). In (b), the ordinate indicates multiples of standard deviation, and the abscissa denotes years. In (c), the ordinate is for the PSD, and the abscissa is for frequency with a unit of cycles per year.

when the time coefficients of EOF1 (Fig. 3b) is positive. The interannual variation is shown in Fig. $3 b$, and Fig. $3 \mathrm{c}$ displays the dominant period of about 5 years. 
In a similar way to the EOF1, the spatiotemporal structure of the second EOF mode (EOF2) was estimated (Fig. 4). The contribution rate of EOF2 to the total variance is $14.8 \%$. The spatial structure is characterized by a dipole with centers over Kyushu and to the southeast of Japan (Fig. 4a). In the years when the time coeffients of EOF2 (Fig. 4b) is positive, the Baiu precipitation tends to increase to the southeast of Japan and to decrease in and around Kyushu. Although the contribution rate of EOF2 is relatively small, it appears to be locally crucial for the Baiu precipitation in and around Kyushu, where the climatological means and the standard deviations are large (Fig. 2). As shown in Figs. $4 \mathrm{~b}$ and $4 \mathrm{c}$, the time variability of EOF2 is differentiated by a quasi-biennial tendency.

The third EOF mode (EOF3) explains $12.3 \%$ of the total variance. The spatial structure of EOF3 displays a monopole pattern with the center near Kyushu and the time coefficients identify a quasi-biennial oscillation (not shown). However, the EOF3 had insignificant correlations with both the ENSO and the TBO of the Asian summer monsoon. In this work, we consider the spatiotemporal structures identified by EOF1 and EOF2.

The predominant periodicity was definitely different between EOF1 (5 years; Fig. 3c) and EOF2 (2 years; Fig. $4 \mathrm{c}$ ), suggesting that the two interannual variations were statistically and physically isolated. Because of these significant periodicity, we can correlate EOF1 with the ENSO and EOF2 with the TBO of the Asian monsoon. To evaluate these correlations, we examined lagged and simultaneous correlations between the EOF time coefficients and variations in SST in the following three regions: (1) the NINO3 region $\left(5^{\circ} \mathrm{S}-5^{\circ} \mathrm{N}\right.$, $90^{\circ}-150^{\circ} \mathrm{W}$ ), (2) the western equatorial Pacific (WEP; $5^{\circ} \mathrm{S}-5^{\circ} \mathrm{N}, 120^{\circ}-140^{\circ} \mathrm{E}$ ), and (3) the northern Indian Ocean (NIO; $\left.0^{\circ}-20^{\circ} \mathrm{N}, 40^{\circ}-100^{\circ} \mathrm{E}\right)$ (Fig. 5). The SST in the NINO3 region is a representative index of the ENSO, whereas the atmospheric counterpart is the Southern Oscillation index. The SST in the NIO also retains the information of the ENSO from winter to summer (Xie et al. 2009). The TBO of the Asian monsoon may be represented by the SST in the WEP (Shen and Lau 1995; Yamaura and Tomita 2011).

Figure 5a shows the statistically significant negative correlations ( $5 \%$ level) between the time coefficients of EOF1 in June and July, and the interannual variation of SST in the NINO3 region from January to April (thick solid line). These negative correlations weaken to an insignificant level by late spring, with the simultaneous correlation in June-July remaining insignificant. The correlations with the interannual variation of SST in the NIO negatively increase and
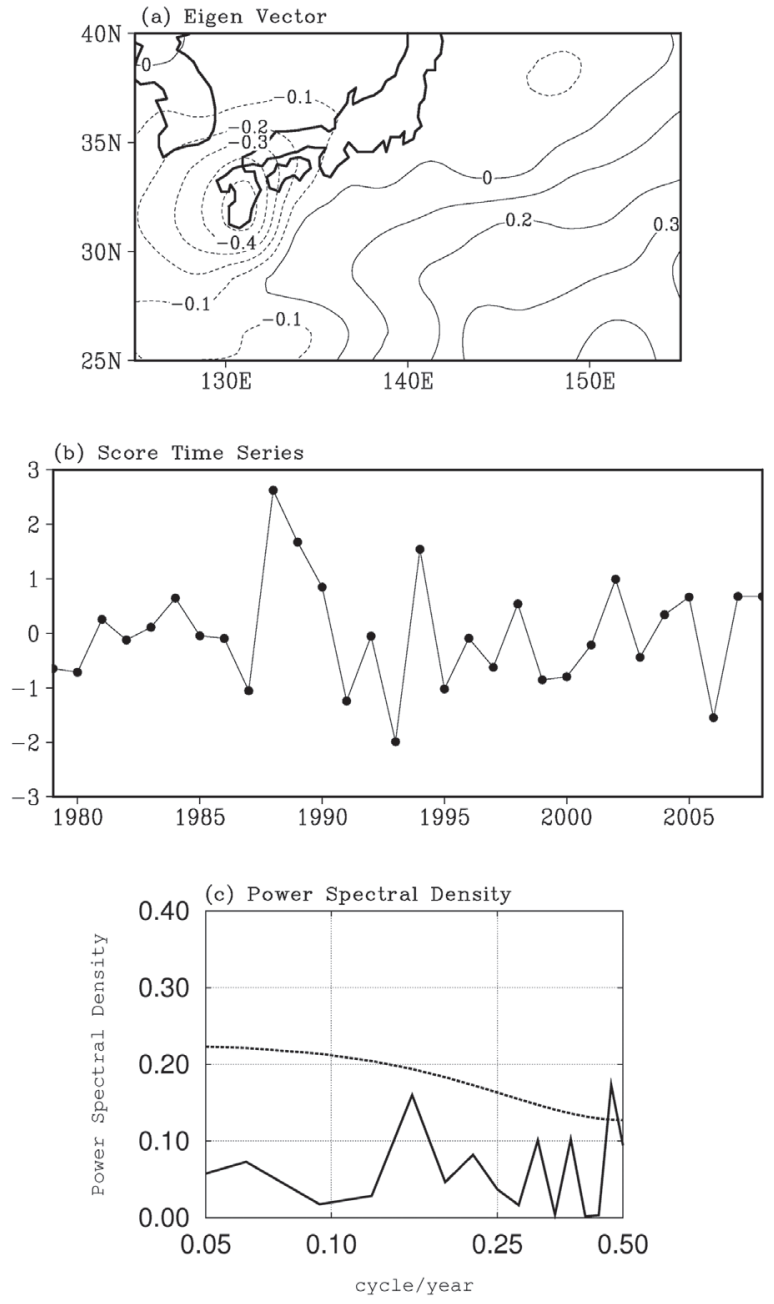

Fig. 4. As in Fig. 3, but for the second EOF mode.

reach its negative peak in August (thin solid line). This lag suggests a role of the NIO as a capacitor, retaining the information on wintertime ENSO events until summer. It is conceivable that the Baiu precipitation is modified by anomalous convection or horizontal atmospheric circulations around the Philippines which are remotely forced by SSTAs in the NIO through propagation of the Kelvin waves (Xie et al. 2009). The PEA teleconnection remained until early summer and may have also contributed to the modification of Baiu precipitation (Wang et al. 2000). Correlations with the interannual SST variation in the WEP are insignificant all year round (dotted line). Hereafter, we refer to EOF1 as the ENSO mode.

Figure 5 b shows similar correlations for EOF2. Statistically significant positive correlations are identified 
(a) EOF 1: ENSO

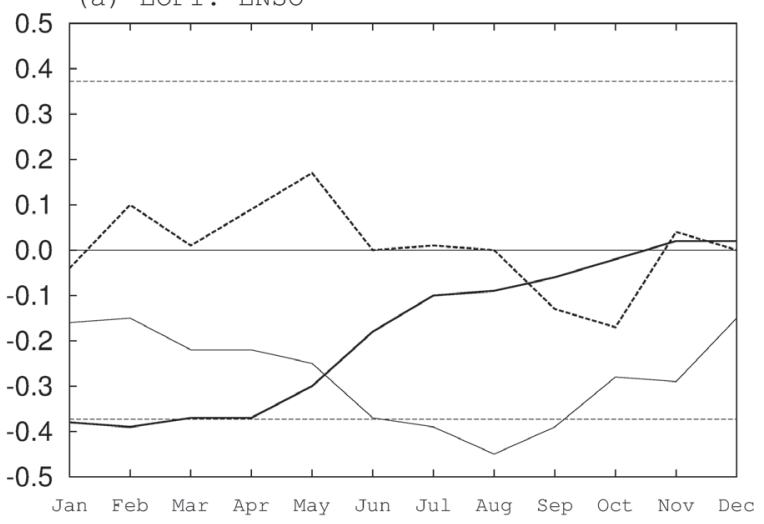

(b) EOF2 : TBO

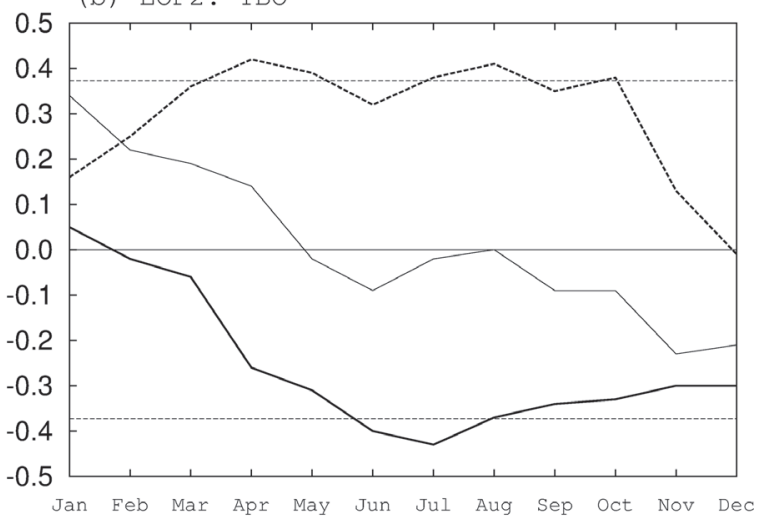

Fig. 5. (a) Lagged and simultaneous correlations between the time coefficients of EOF1 and the SST (HadISST) in the NINO3 region $\left(5^{\circ} \mathrm{S}-5^{\circ} \mathrm{N}\right.$, $90^{\circ}-150^{\circ} \mathrm{W}$; thick solid line), the WEP $\left(5^{\circ} \mathrm{S}-5^{\circ} \mathrm{N}\right.$, $120^{\circ}-140^{\circ} \mathrm{E}$; dotted line), and the NIO $\left(0^{\circ}-20^{\circ} \mathrm{N}\right.$, $40^{\circ}-100^{\circ} \mathrm{E}$; thin solid line). Horizontal dotted lines denote 5\% significance. (b) Similar correlations, but with the time coefficients of EOF2.

for the SST in the WEP from March to October, except for June and September, although those two months almost reach the significance level (dotted line). Conversely, correlations with the SST in the NINO3 region (thick solid line) are significantly negative in June and July, while those of the NIO (thin solid line), which show a negative slope and change from positive to negative over a year, are insignificant. These lagged and simultaneous correlations imply that when EOF2 is positive (Fig. 4a), positive SSTAs are likely to appear in the NIO and WEP during the preceding winter. By spring, the SSTAs in the NIO become small, while those in the WEP are stably positive. In June and July, negative SSTAs appear in the NINO3 region, creating a nega- tive slope in SSTAs in the equatorial Pacific, similar to a cold ENSO event. This zonal SSTA gradient remains during summer in the equatorial Pacific, while the SSTAs in the NIO change their sign in summer. These systematic variations in the SSTAs correspond to the nature of the TBO of the Asian monsoon, as shown by Kawamura et al. (2003). The TBO is particularly detectable in decades after the climatic regime shift, occurring in the second half of the 1970s (e.g., Shen and Lau 1995; Tomita and Yasunari 1996; Lau and Wu 2001; Tomita et al. 2004; Yamaura and Tomita 2011). Hereafter, we refer to EOF2 as the TBO mode.

In addition, this work defines the $\mathrm{L}(\mathrm{E})$ pattern in the ENSO and TBO modes as La Niña-like (El Niñolike) distributions of SSTAs; that is, negative (positive) SSTAs appear in the eastern tropical Pacific when this pattern is dominant. On the basis of this definition, EOF1 (the ENSO mode), which correlates with the ENSO, is divided into two patterns depending on the polarity. One pattern is similar to La Niña in cases when the time coefficients are positive; this is referred to as ENSO/L. The other is the opposite pattern, identical to El Niño; which is abbreviated as ENSO/E. In the same way, EOF2 (the TBO mode) is separated into two patterns, TBO/L and TBO/E, using SSTAs in the eastern tropical Pacific. The years included in each mode are shown in Table 1.

Tomita et al. (2004) and Yamaura and Tomita (2011) pointed out that the Baiu precipitation anomalies are largely modified by tropical and subtropical lower atmospheric circulations associated with the ENSO and the TBO. Figure 6 shows precipitation rate anomalies (shaded), stream function anomalies at $850 \mathrm{hPa}$ (contours), and stationary wave activity fluxes $(\boldsymbol{W})$ estimated in anomaly fields (vectors). $\boldsymbol{W}$ indicates the energy propagation of stationary Rossby waves with a direction parallel to that of group velocity, expressed in the horizontal field (Takaya and Nakamura 2001) by

$$
\boldsymbol{W}=\frac{p}{2|\boldsymbol{U}|}\left(\begin{array}{l}
U\left(\psi_{x}^{2}-\psi \psi_{x x}\right)+V\left(\psi_{x} \psi_{y}-\psi \psi_{x y}\right) \\
U\left(\psi_{x} \psi_{y}-\psi \psi_{x y}\right)+V\left(\psi_{y}^{2}-\psi \psi_{y y}\right)
\end{array}\right),
$$

where $p=($ pressure $/ 1000 \mathrm{hPa}) ; \boldsymbol{U}=(U, V)^{\mathrm{T}}$, which is a steady zonally inhomogeneous basic flow; and $\psi$ indicates stream function anomalies. Subscripts in $\psi$ denote partial derivatives.

The anomaly fields associated with the ENSO mode (Fig. 6a), in which the anomalies were estimated from the difference between ENSO/L and EN$\mathrm{SO} / \mathrm{E}(\mathrm{ENSO} / \mathrm{L}-\mathrm{ENSO} / \mathrm{E})$, reveal that precipitation rate anomalies were negative in the region stretching 
Table 1. Composite years for ENSO/L, ENSO/E, TBO/L, and TBO/E, based on polarities in the time coefficients of EOF1 (Fig. 3b) and EOF2 (Fig. 4b). For brevity, the final two figures are listed for years.

\begin{tabular}{ccccccccccc}
\hline \multicolumn{10}{c}{ composite year } \\
\hline ENSO/L & 80 & 81 & 84 & 85 & 90 & 91 & 96 & 01 & 04 & 08 \\
ENSO/E & 82 & 83 & 95 & 98 & 99 & 00 & 02 & 03 & 05 & 07 \\
TBO/L & 84 & 88 & 89 & 90 & 94 & 98 & 02 & 05 & 07 & 08 \\
TBO/E & 79 & 80 & 87 & 91 & 93 & 95 & 97 & 99 & 00 & 06 \\
\hline
\end{tabular}

northeastward from southeastern China toward the east of Japan, and were positive in and around the Yellow Sea. This pattern corresponds to the eigenvector pattern of EOF1 (Fig. 3a). Additionally, regions with positive precipitation rate anomalies extend zonally toward the south of the negative anomalies, which trace back farther to the Indian subcontinent. In the atmospheric circulation fields, an anomalous anticyclone is observed near $\left(30^{\circ} \mathrm{N}, 130^{\circ} \mathrm{E}\right)$, and two anomalous cyclones are centered near $\left(15^{\circ} \mathrm{N}, 123^{\circ} \mathrm{E}\right)$ and $\left(25^{\circ} \mathrm{N}\right.$, $157^{\circ} \mathrm{E}$ ). Using a geostrophic approximation, it is expected that southwesterly (northeasterly) winds will occur around the northwestern (southeastern) part of an anticyclone and around the southeastern (northwestern) part of a cyclone. Regions with anomalous southwesterly (northeasterly) winds are also regions with anomalous convergence (divergence) and ascent (descent) within the lower troposphere, resulting in anomalous precipitation rates at these locations (Yamaura and Tomita 2011). This relationship is also confirmed in Fig. 6a. Because two anomalous cyclones modify the axis of the monsoon westerlies southward in the WNP, negative precipitation rate anomalies are exhibited in the Baiu front where water vapor fluxes are weakened (Fig. 6a). In addition, $\boldsymbol{W}$ diverges around the two anomalous cyclones in the WNP and converges with the anomalous anticyclonic center near Kyushu, suggesting that the anomalous anticyclone is formed by energy propagation of stationary Rossby waves associated with the two anomalous cyclones. The configuration of the anomalous circulations in the WNP is critical for the ENSO mode, which largely modifies precipitation along the Baiu front (Figs. 3a, 6a).

Figure $6 \mathrm{~b}$ shows the anomalies associated with the TBO mode, which were estimated using a similar differential technique (TBO/L - TBO/E). Positive anomalies in precipitation rate extend to the southeast of Japan $\left(25^{\circ} \mathrm{N}, 150^{\circ} \mathrm{E}\right)$, whereas negative anomalies appear from the East China Sea to Japan. This pattern in precipitation rate anomalies reflects that of the eigenvector of EOF2 (Fig. 4a). We can also identify

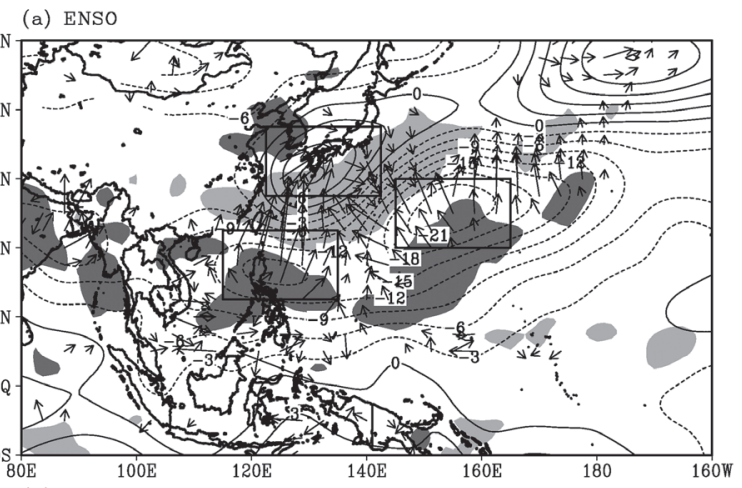

(b) ТВO

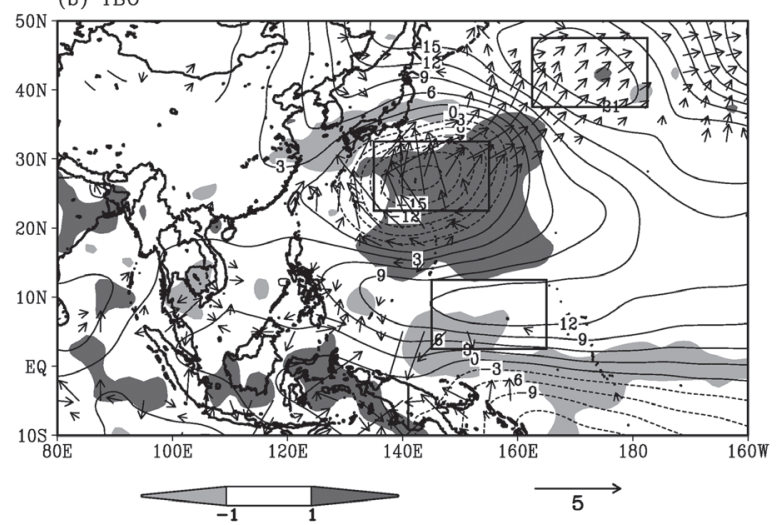

Fig. 6. (a) Differential anomalies of precipitation rate ( $\mathrm{mm}$ day $^{-1}$; shading; GPCP), stream function $\left(10^{5} \mathrm{~m}^{2} \mathrm{~s}^{-1}\right.$; contour; JRA-25/JCDAS $)$ at $850 \mathrm{hPa}$, and the wave activity fluxes $\left(\boldsymbol{W} ; \mathrm{m}^{2} \mathrm{~s}^{-2}\right.$; vector) associated with the ENSO mode in JuneJuly. The contour interval is $3.0 \times 10^{5} \mathrm{~m}^{2} \mathrm{~s}^{-1}$, and the dotted contours denote negative values. Shading and vector scales are given below the lower panel. The Tibetan Plateau higher than 1,500 m and vectors less than $0.5 \mathrm{~m}^{2} \mathrm{~s}^{-2}$ are omitted for clarity. (b) Similar to (a) but for the TBO mode. Rectangles in each panel indicate the centers of anomalous atmospheric circulations. 
positive anomalies along the equator for longitudes $80^{\circ}-140^{\circ} \mathrm{E}$, while the negative anomalies extend to the east. This equatorial pattern probably reflects the anomalous Walker circulation concurrent with the TBO of the Asian monsoon through the zonal SST gradient in the western equatorial Pacific (Fig. 5b). In the anomalous atmospheric circulation, a large anomalous cyclone is identified to the southeast of Japan around $\left(27^{\circ} \mathrm{N}, 143^{\circ} \mathrm{E}\right)$, and two anomalous ridges centered at $\left(8^{\circ} \mathrm{N}, 155^{\circ} \mathrm{E}\right)$ and $\left(44^{\circ} \mathrm{N}, 175^{\circ} \mathrm{E}\right)$ surround it, except westward. Positive precipitation rate anomalies are associated with the anomalous cyclone, particularly in the southeastern portion where anomalous southwesterly winds are expected. A small region with negative precipitation rate anomalies extends in the northwestern area near Japan with geostrophic northeasterlies. The relatively large anomalous cyclone to the southeast of Japan shifts southward the axis of the monsoon westerlies in the WNP. Additionally, $\boldsymbol{W}$ diverges northeastward from the anomalous cyclone to the adjacent anomalous anticyclone around $\left(44^{\circ} \mathrm{N}, 175^{\circ} \mathrm{E}\right)$. The size of $\boldsymbol{W}$ is small in the tropics to the south of the anomalous cyclone, indicating that it is not being forced by atmospheric circulations in the tropics through stationary Rossby waves. The anomalous cyclone to the southeast of Japan is probably a key element in controlling variations in the Baiu precipitation for the TBO mode.

\section{Typical large-scale interannual variations and tropical cyclone activity in the western North Pacific during the Baiu season}

In this section we examine how the ENSO and the TBO of the Asian monsoon modulate TC activity in the WNP during the Baiu season, June and July. As indices of TC activity, this work employs the NTC and the ACE, which were estimated from the 6-hourly data of TCs aggregated by the JTWC. First, the climatologies of the NTC and the ACE are described in the WNP.

Figure 7 shows the long-term (1979-2008; 30 years) means of the NTC, the ACE, and the ratio of ACE to NTC (ACE/NTC) in the WNP in June and July. This work employed both the NTC and the ACE to evaluate the strength of atmospheric circulations associated with TCs. The investigations show that the ACE behaves proportionally to the NTC (Figs. 7a, b), and ACE/NTC indicates the mean ACE of a TC in an area (Fig. 7c).

The climatological NTC in June-July is large in the northern half of the South China Sea and in the region extending southeastward, both of which have large number values greater than 2 (Fig. 7a). This indicates that in one year, there are two TCs in June-July. Note (a) NTC

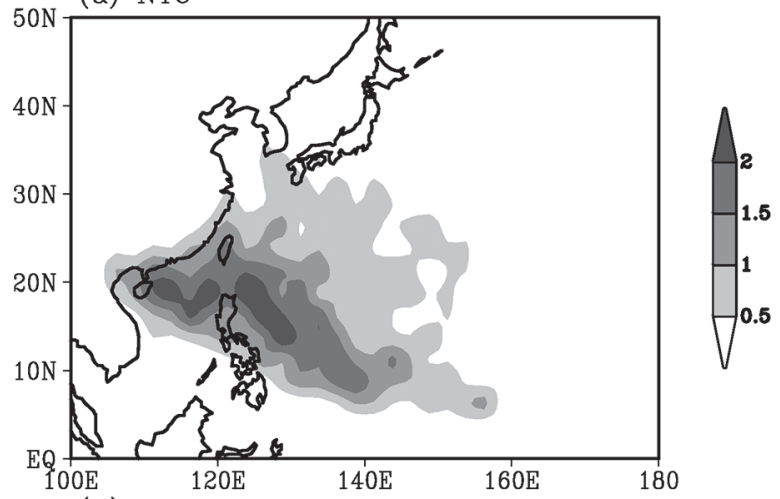

(b) $\mathrm{ACE}$

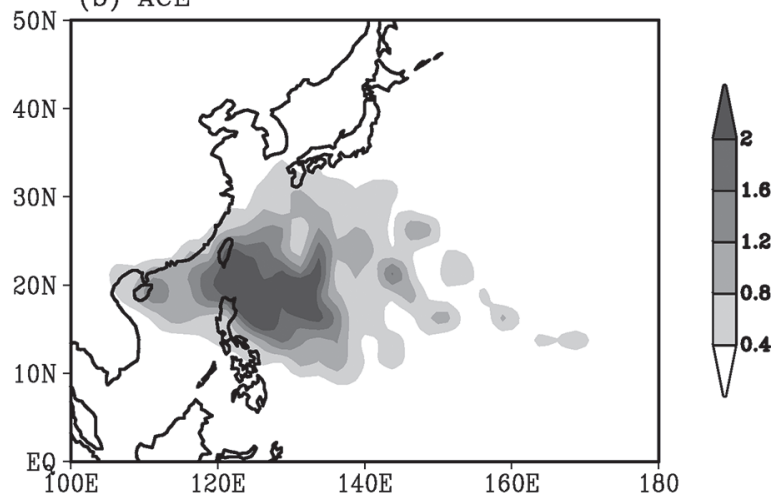

(c) $\mathrm{ACE} / \mathrm{NTC}$

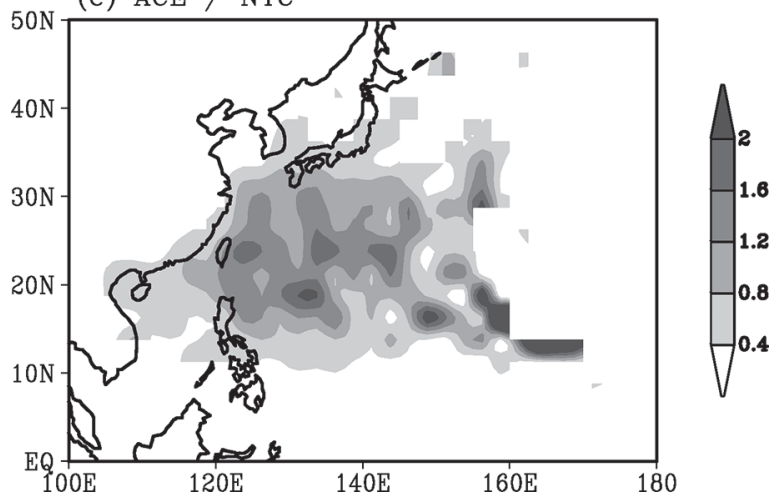

Fig. 7. (a) Long-term (1979-2008; 30 years) means of NTC (no unit) and (b) ACE $\left(10^{3} \mathrm{~m}^{2} \mathrm{~s}^{-2}\right)$, and (c) the ratio of ACE to NTC (ACE/NTC; $10^{3} \mathrm{~m}^{2} \mathrm{~s}^{-2}$ ) during June-July, estimated from the JTWC data (244 data for each year: 61 days $\times 4$ times daily). Note that the NTC is not the number of TC geneses but the number of TCs existing in a grid box of $2.5^{\circ} \times 2.5^{\circ}$. The shading scale is shown at the right of each panel.

that the number is counted in a region of $2.5^{\circ} \times 2.5^{\circ}$, and we also need to consider the existence period for TCs in the region. Regions with the NTC values of 0.5 
(a) ENSO : NTC

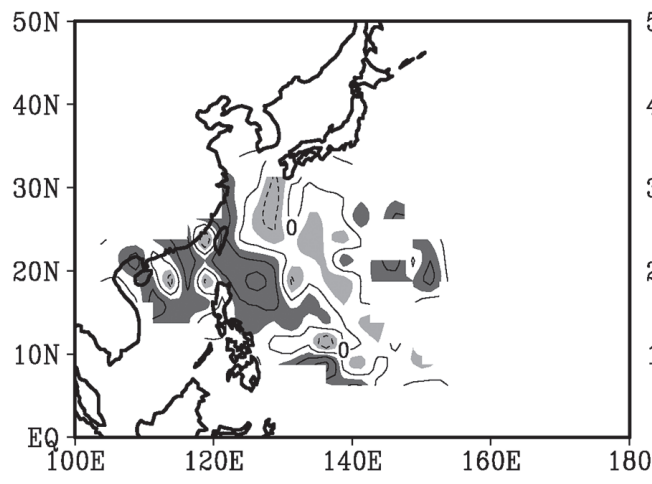

(c) TBO : NTC

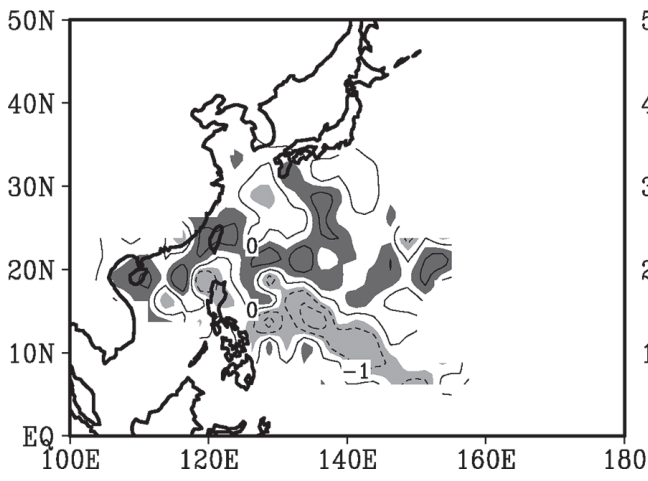

(b) ENSO : $\mathrm{ACE}$

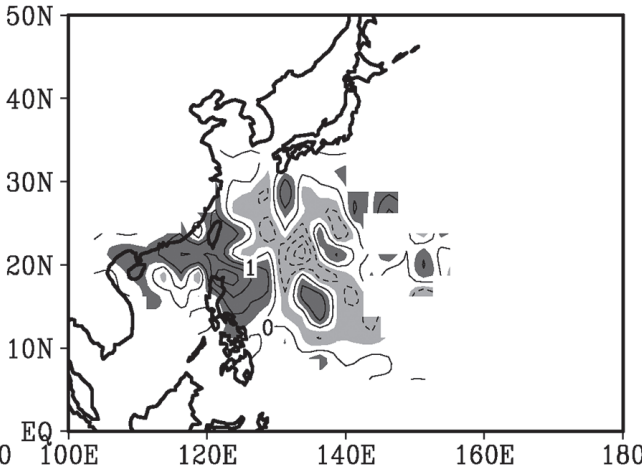

(d) TBO : $\mathrm{ACE}$

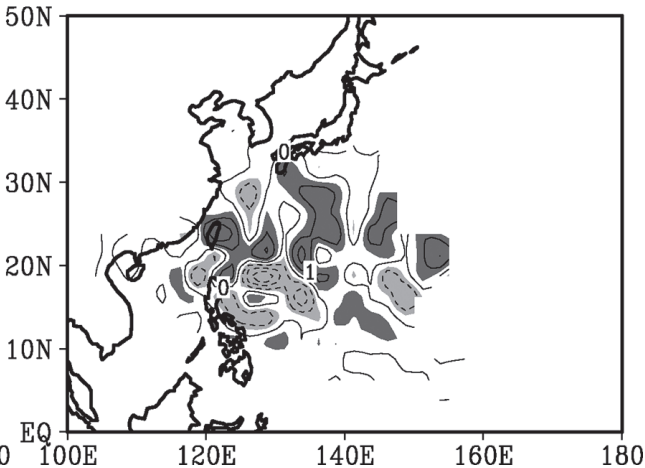

Fig. 8. Spatial distributions of anomalies in the NTC [(a), (c)] and the ACE [(b), (d)] in June-July associated with the ENSO (upper panels) and the TBO (lower panels), which are estimated from the JTWC data. The contour interval is 1.0 (no unit) in [(a), (c)] and $1.0 \times 10^{3} \mathrm{~m}^{2} \mathrm{~s}^{-2}$ in $[(\mathrm{b}),(\mathrm{d})]$. The dotted contours denote the negative values in the four panels. Dark (light) shades indicate the regions with the values larger than 0.5 (less than -0.5$)$ in [(a), (c)] and those larger than $0.5 \times 10^{3} \mathrm{~m}^{2} \mathrm{~s}^{-2}$ (less than $-0.5 \times 10^{3} \mathrm{~m}^{2} \mathrm{~s}^{-2}$ ) in [(b), (d)].

or larger extend to the south of Japan, with a part reaching the Korean Peninsula. Mean ACE values are largest (exceeding $2.0 \times 10^{3} \mathrm{~m}^{2} \mathrm{~s}^{-2}$ ) to the east of Taiwan and around Luzon Island of the Philippines in the WNP (Fig. 7b). The region with large ACE corresponds to that with large NTC, except at the southeastern margin around $\left(8^{\circ} \mathrm{N}, 140^{\circ} \mathrm{E}\right)$. This difference indicates that the maximum wind speed of the TC is relatively small, either because the TCs do not sufficiently develop or they are not well organized at lower latitudes. In Fig. $7 \mathrm{c}, \mathrm{ACE} / \mathrm{NTC}$ is large in a band of $15^{\circ}-30^{\circ} \mathrm{N}$ in the WNP. This region is different from the region in which large NTC values appears (Fig. 7a). This difference, in turn, suggests that TCs develop and move north or northwestward and reach maximum wind speed around $15^{\circ}-30^{\circ} \mathrm{N}$ in the WNP. Note that the extremely large values to the north of the Marshall Islands are due to the small NTC values there.

Whereas previous studies have focused on the re- lationship between the ENSO and TC activity in the WNP (e.g., Chan 2000, 2007; Wang and Chan 2002; Camargo and Sobel 2005), this work focuses on TC activity during the Baiu season and examines how the NTC and the ACE during this season are modulated by the ENSO and the TBO. Figure 8 shows the NTC and ACE anomalies for June-July associated with the ENSO and TBO modes (Figs. 3, 4). With respect to the ENSO mode, regions with positive NTC anomalies extend from the northern part of the South China Sea to the east of Luzon Island, and those with negative anomalies appear to the south of Japan (Fig. 8a). The spatial pattern of ACE anomalies in the ENSO mode (Fig. 8b) is similar to that of NTC anomalies, with both displaying an east-west dipole-like pattern with a meridional axis around $130^{\circ} \mathrm{E}$. This implies a zonal shift of TC activity associated with the phases of the ENSO mode. This anomalous pattern indicates that the ACE tends to increase (decrease) around the Philippines 
Table 2. Areal means of the NTC for the regions shown by rectangles in Figs. 6a and 6b. The following statistics are also listed: Student's t-value $(t)$, degrees of freedom $(D F)$, and probability value $(p)$. The regions cover the following areas: $\mathrm{A}\left(12.5^{\circ}-22.5^{\circ} \mathrm{N}, 115^{\circ}-135^{\circ} \mathrm{E}\right)$, B $\left(20^{\circ}-30^{\circ} \mathrm{N}, 145^{\circ}-165^{\circ} \mathrm{E}\right), \mathrm{C}\left(27.5^{\circ}-37.5^{\circ} \mathrm{N}, 122.5^{\circ}-142.5^{\circ} \mathrm{E}\right), \mathrm{D}\left(2.5^{\circ}-12.5^{\circ} \mathrm{N}\right.$, $\left.145^{\circ}-165^{\circ} \mathrm{E}\right), \mathrm{E}\left(22.5^{\circ} \mathrm{N}-32.5^{\circ} \mathrm{N}, 135^{\circ}-155^{\circ} \mathrm{E}\right)$, and $\mathrm{F}\left(37.5^{\circ}-47.5^{\circ} \mathrm{N}, 162.5^{\circ}-182.5^{\circ} \mathrm{E}\right)$. In the column of $p$, boldface text indicates significance at the $5 \%$ level $(p<0.05)$.

\begin{tabular}{cccccc}
\hline Region & ENSO/L & ENSO/E & $t$ & $D F$ & $p$ \\
\hline A & 57.3 & 38.1 & 2.36 & 18 & $\mathbf{0 . 0 3}$ \\
B & 15.5 & 5.6 & 2.00 & 14 & 0.08 \\
C & 12.9 & 13.9 & -0.18 & 15 & 0.86 \\
\hline Region & TBO/L & TBO/E & $t$ & $D F$ & $p$ \\
\hline D & 9.9 & 18.1 & -1.17 & 18 & 0.27 \\
E & 16.4 & 11.6 & 0.89 & 18 & 0.40 \\
F & 0.3 & 0.6 & -0.47 & 11 & 0.65 \\
\hline
\end{tabular}

after a La Niña (El Niño) event (Camargo and Sobel 2005).

With respect to the TBO mode, positive NTC anomalies extend to the north of $17^{\circ} \mathrm{N}$, while negative anomalies extend to the south (Fig. 8c). This meridional dipole suggests that anomalous TC genesis in JuneJuly systematically shifts in the meridional direction with the TBO mode, unlike the zonal shift observed in the ENSO mode. The spatial pattern in ACE anomalies (Fig. 8d) also displays a similar meridional dipole straddling $17^{\circ} \mathrm{N}$ in the WNP, although negative anomalies are small around $10^{\circ} \mathrm{N}$. The small values are probably caused by weak TCs to the south of $10^{\circ} \mathrm{N}$.

To better evaluate the influences of the ENSO and TBO on TC activity in the WNP, we examined how atmospheric circulation anomalies associated with the ENSO and the TBO correlate with the TC activity. To choose the specific regions, we again pay attention to the areas (boxes) where large anomalies of stream function at $850 \mathrm{hPa}$ appeared in Fig. 6. For each of the six boxes, the areal means of the NTC and the ACE in June-July were estimated for the years in Table 1. From this the following three statistics were calculated: (1) Student's $t$-value $(t),(2)$ degrees of freedom $(D F)$, and (3) probability value ( $p$ ) (Press et al. 1992), each of which is expressed by

$$
t=\frac{\frac{1}{n^{L}} \sum X_{A}^{L}-\frac{1}{n^{E}} \sum X_{A}^{E}}{\sqrt{\frac{\left(\sigma_{A}^{L}\right)^{2}}{n^{L}}-\frac{\left(\sigma_{A}^{E}\right)^{2}}{n^{E}}}},
$$

$$
\begin{gathered}
D F=\frac{\left(\frac{\left(\sigma_{A}^{L}\right)^{2}}{n^{L}}-\frac{\left(\sigma_{A}^{E}\right)^{2}}{n^{E}}\right)^{2}}{\frac{1}{n^{L}-1}\left(\frac{\left(\sigma_{A}^{L}\right)}{n^{L}}\right)^{2}+\frac{1}{n^{E}-1}\left(\frac{\left(\sigma_{A}^{E}\right)}{n^{E}}\right)^{2}}, \\
p=P D F(t, D F),
\end{gathered}
$$

where

$$
\begin{gathered}
\sigma_{A}^{L}=\sqrt{\frac{1}{n^{L}-1} \sum\left(X_{A}^{L}-\frac{1}{n^{L}} \sum X_{A}^{L}\right)^{2}}, \\
\sigma_{A}^{E}=\sqrt{\frac{1}{n^{E}-1} \sum\left(X_{A}^{E}-\frac{1}{n^{E}} \sum X_{A}^{E}\right)^{2}} .
\end{gathered}
$$

In these equations, $X$ denotes the value of NTC or ACE in each year. Subscript $A$ indicates the names of the chosen boxes (A-F), whereas superscript, L (E), indicates the years of $\mathrm{ENSO} / \mathrm{L}(\mathrm{E})$ or TBO/L (E). $n$ denotes the number of years in each case of ENSO/L (E) and TBO/L (E) $\left(n^{L}=n^{E}=10\right.$ in this work). PDF is the probability density function of the Student's $t$-distribution.

The results for areal means of the NTC are shown in Table 2. In Region A, the difference between areal mean NTC values for ENSO/L and ENSO/E is 19.2, which is significant at the $5 \%$ level. This difference indicates that the areal mean NTC in Region A is significantly large for ENSO/L compared to that for ENSO/E (Figs. 8a, b). This implies that TC activity, related to the number of TCs, covaries to the formation of an anomalous cyclone around the Philippines 
Table 3. As in Table 2, but for ACE.

\begin{tabular}{cccccc}
\hline Region & ENSO/L & ENSO/E & $t$ & $D F$ & $p$ \\
\hline A & 56437 & 42827 & 1.20 & 17 & 0.25 \\
B & 14244 & 5264 & 1.30 & 15 & 0.21 \\
C & 12898 & 11358 & 0.30 & 17 & 0.77 \\
\hline Region & TBO/L & TBO/E & $t$ & $D F$ & $p$ \\
\hline D & 3305 & 2635 & 0.24 & 11 & 0.83 \\
E & 20518 & 6567 & 2.35 & 14 & $\mathbf{0 . 0 4}$ \\
F & 150 & 351 & -0.55 & 11 & 0.62 \\
\hline
\end{tabular}

Table 4. Total numbers of composite days in June-July employed to estimate the anomalies in ALL, EXT, and WIT.

\begin{tabular}{ccccc}
\hline & ENSO/L & ENSO/E & TBO/L & TBO/E \\
\hline ALL & 610 & 610 & 610 & 610 \\
EXT & 469 & 524 & 572 & 578 \\
WIT & 141 & 86 & 38 & 32 \\
\hline
\end{tabular}

(Fig. 6a). In the areal means of the ACE results (Table 3 ), the only significant anomaly (at the 5\% level) appears in Region E; this demonstrates that the ACE in this region is significantly large in $\mathrm{TBO} / \mathrm{L}$ compared with that in TBO/E (Figs. 8c, d). This suggests that the TC activity, related to the strength of TCs, covaries to the anomalous cyclone to the southeast of Japan (Fig. $6 \mathrm{~b})$. Note that the areal means of "ACE" in Region A and that of "NTC" in Region E are insignificant. The former suggests that the strength of TCs in Region A is weak in the ENSO mode, while the latter implies that difference in TC numbers in Region $\mathrm{E}$ is insignificant between TBO/L and TBO/E. Thus, the characters of TC activity correlating to anomalous circulations are different between the ENSO and TBO modes.

5. Covariability between the Baiu precipitation and tropical cyclone activity in the western North Pacific through large-scale atmospheric circulations

This section examines how the anomalous atmospheric circulations associated with the ENSO and the TBO conduct covariability between the Baiu precipitation and TC activity in the WNP. That is, coherence between the results of Sections 3 and 4 is diagnosed. To approach this issue, we used the 6-hourly TC data from JTWC, the daily mean OLR compiled at NOAA, and the 6-hourly stream function at $850 \mathrm{hPa}$ in the JRA-25/ JCDAS reanalysis datasets. Using these data, the following three anomaly fields were calculated: (1) anom- alies using all the data during June-July, which correspond to those estimated from monthly mean data; (2) anomalies of days when TCs were not observed in specific regions; and (3) anomalies for days when TCs were observed in specific regions. The specific regions investigated were Region A in the ENSO mode and Region $\mathrm{E}$ in the TBO mode. Hereafter, we call these three anomaly fields (1) ALL, (2) EXT, and (3) WIT, respectively, in which the later two are from "except for" and "with" TCs. These three anomaly fields were calculated on the basis of time coefficients representing the ENSO and TBO modes (Figs. 3b, 4b). The composite days for the four cases, ENSO/L, ENSO/E, TBO/L, and $\mathrm{TBO} / \mathrm{E}$, are listed in Table 4. The three anomaly fields were estimated based on the long-term (1979-2008; 30 years) means for the four cases. Note that atmospheric circulation anomalies in WIT are always cyclonic near specific regions where TCs are strong regardless of the ENSO and TBO mode phases.

The ENSO mode shows a significant difference in Region A with respect to areal mean of NTC (Table 2). On the basis of this difference, we examined the anomaly fields of OLR and stream function at $850 \mathrm{hPa}$ in the cases of $\mathrm{ENSO} / \mathrm{L}$ and $\mathrm{ENSO} / \mathrm{E}$ (Fig. 9). In ALL (Fig. 9a), we found positive OLR anomalies extending northeastward from the East China Sea to the east of Japan, which suggested weaker-than-normal convection. Accompanying the positive region were two negative regions one to the northwest and the other to the southeast. The stream function anomalies at 850 
(a) ENSO/L : ALL

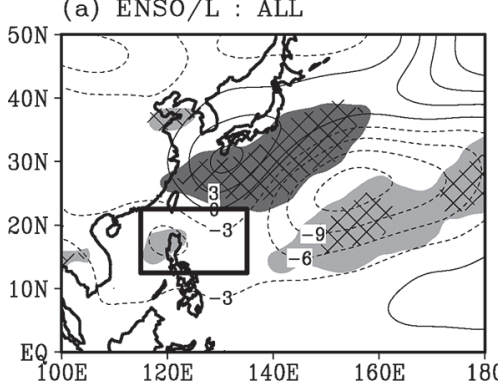

(d) $\mathrm{ENSO} / \mathrm{E}:$ ALL

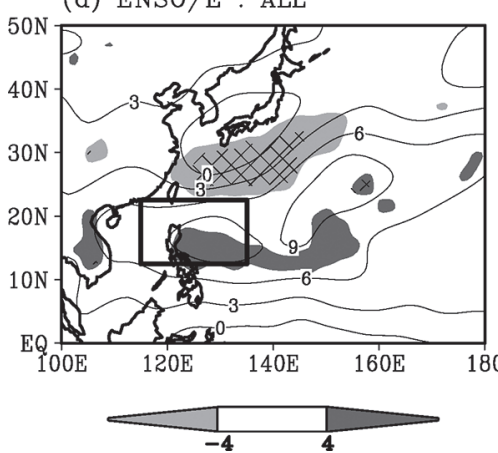

(b) ENSO/L : EXT

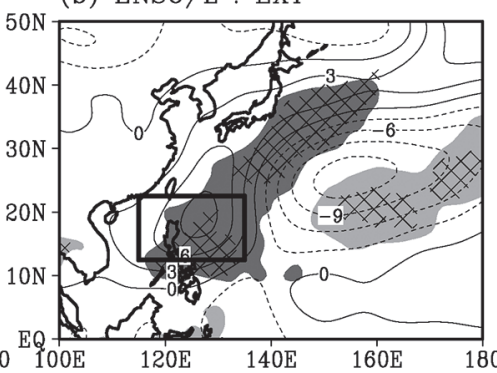

(e) $\mathrm{ENSO} / \mathrm{E}: \mathrm{EXT}$

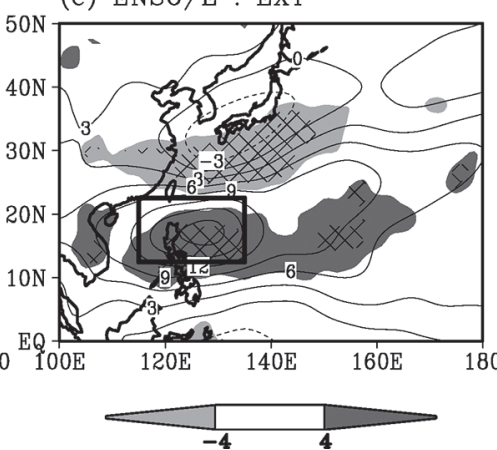

(c) ENSO/L : WIT

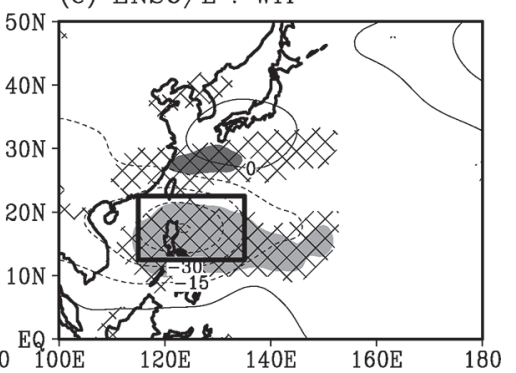

(f) $\mathrm{ENSO} / \mathrm{E}: \mathrm{WIT}$

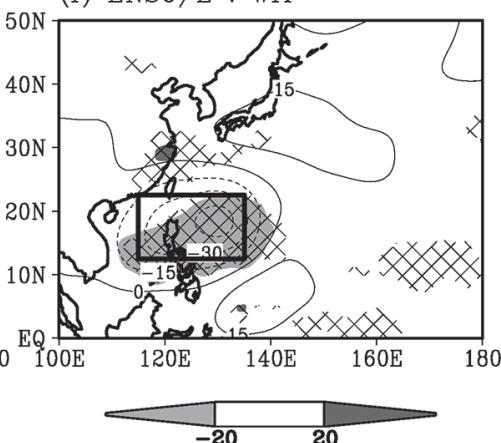

Fig. 9. OLR anomalies ( $\mathrm{W} \mathrm{m}^{-2}$; shading with hatch) and stream function anomalies $\left(10^{5} \mathrm{~m}^{2} \mathrm{~s}^{-1}\right.$; contour) at 850 $\mathrm{hPa}$ associated with ENSO/L (upper panels) and ENSO/E (lower panels). See text for descriptions of ALL (left), EXT (center), and WIT (right). All panels indicate anomalies for different numbers of days in June-July (Table 4) from the long-term (1979-2008; 30 years) means. The scales of shading for each column are displayed at the bottom of panels. Hatched regions indicate significant OLR anomalies at the 5\% level with one-sided test. The contour interval is $3.0 \times 10^{5} \mathrm{~m}^{2} \mathrm{~s}^{-1}$ for the contours in left and center panels and $1.5 \times 10^{6} \mathrm{~m}^{2} \mathrm{~s}^{-1}$ in right panels. The dotted contours signify negative anomalies.

$\mathrm{hPa}$ indicate an anomalous anticyclone around western Japan and a larger anomalous cyclone to the southeast $\left(27^{\circ} \mathrm{N}, 155^{\circ} \mathrm{E}\right)$. These OLR and stream function patterns correspond to the precipitation and stream function anomalies shown in Fig. 6a. In EXT (Fig. 9b), the OLR and stream function anomalies explain those in ALL to the east of $140^{\circ} \mathrm{E}$. However, the differences are large to the west of $140^{\circ} \mathrm{E}$, particularly in Region A. The positive OLR anomalies in Region A suggest an anomalous decrease in convective activity. In the stream function anomaly field, differences in Region A indicate the presence of an anomalous anticyclone. To the west of $140^{\circ} \mathrm{E}$, the OLR and stream function anomalies of WIT (Fig. 9c) seem to contribute to the anomalies of ALL (Fig. 9a). The negative OLR and stream function anomalies around the Philippines and positive anomalies near southwestern Japan are similar to the Pacific-Japan (PJ) pattern of a stationary Rossby wave train, which is sometimes excited by TCs (Kawamura and Ogasawara 2006; Yamada and Kawamura 2007).
This pattern enhances atmospheric circulations around western Japan. To make the anomalous atmospheric circulations to the west of $140^{\circ} \mathrm{E}$ in ALL (Fig. 9a), the PJ pattern, which is plausibly forced by TC activity in Region A, is required. Thus, TC activity in Region A (Fig. 9c) modifies the anomalies to the west of $140^{\circ} \mathrm{E}$ in days without TCs (Fig. 9b), and covaries with largescale atmospheric circulation anomalies of ENSO/L for monthly mean fields (Fig. 9a).

In the case of ENSO/E, the patterns of OLR and stream function anomalies in ALL (Fig. 9d) are similar to those of ENSO/L (Fig. 9a) but with opposite polarity. Negative OLR anomalies extend along $28^{\circ} \mathrm{N}$ in the WNP and are accompanied with small positive anomalies to the south. The stream function anomalies reveal an anomalously large anticyclone that stretches northeastward from the Philippines to the International Date Line. In EXT (Fig. 9e), the OLR anomalies are consistent with those in ALL, which are significantly enhanced. The pattern of stream function anomalies in 
(a) $\mathrm{TBO} / \mathrm{L}: \mathrm{ALL}$

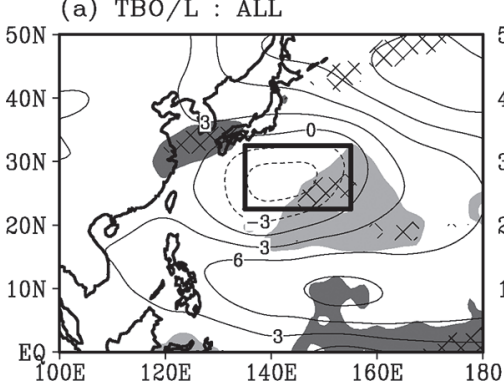

(b) TBO/L : EXT

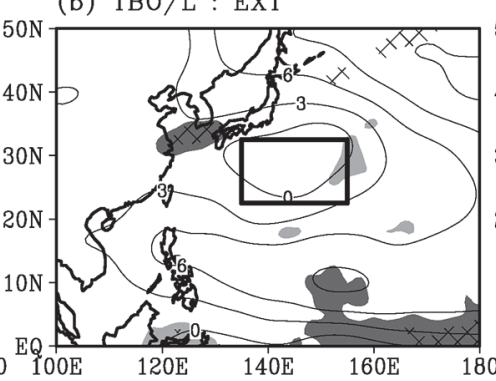

(c) TBO/L : WIT

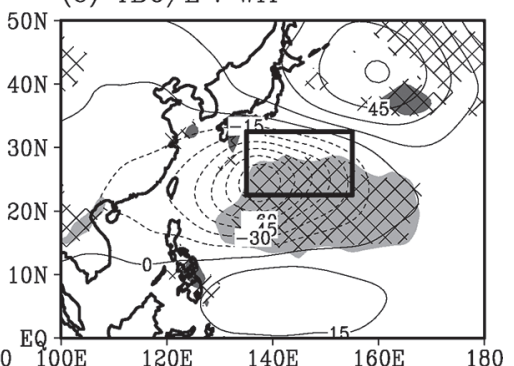

(d) TBO/E : ALL

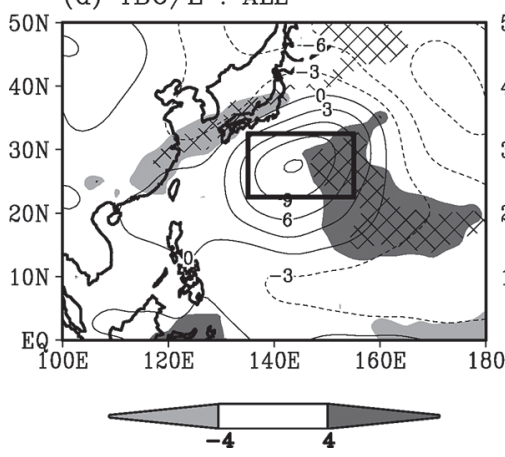

(e) TBO/E : EXT

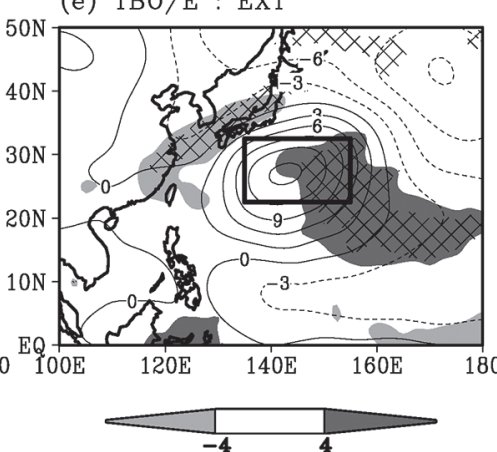

(f) $\mathrm{TBO} / \mathrm{E}: \mathrm{WIT}$

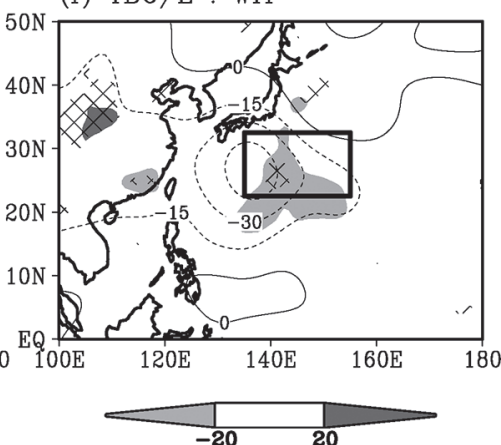

Fig. 10. As in Fig. 9, but for TBO/L (upper panels) and TBO/E (lower panels).

EXT is similar to that in ALL. The OLR anomalies in WIT (Fig. 9f) indicate enhanced convection around the Philippines, and the stream function anomalies display an anomalous cyclone close to the Philippines. The spatial patterns of OLR and stream function anomalies in WIT are inconsistent with those patterns in ALL and EXT. Thus, the large-scale atmospheric circulation anomalies without TCs in Region A (Fig. 9e) largely contribute to constructing the pattern of OLR and stream function anomalies of ENSO/E (Fig. 9d). This is because the covariation with TCs in Region A is small, or negative to the anomalies observed in EN$\mathrm{SO} / \mathrm{E}$. In the ENSO mode, the NTC in Region A (Table 2) seems to determine the strength of the anomalous cyclone around the Philippines in WIT, which is stronger in ENSO/L (Fig. 9c) than in ENSO/E (Fig. 9f).

We then examined the anomaly fields associated with the TBO mode, and TC activity in Region E, which demonstrated a significant difference in the ACE between TBO/L and TBO/E (Fig. 10). In ALL for TBO/L (Fig. 10a), the spatial pattern of OLR anomalies is characterized by positive anomalies over the East China Sea and near the equator (east of $140^{\circ} \mathrm{E}$ ). Regions with negative OLR anomalies can be seen to the southeast of Japan, centered at $\left(22^{\circ} \mathrm{N}, 155^{\circ} \mathrm{E}\right)$. The pattern of stream function anomalies indicated that an anomalous cyclone extended to the southeast of Japan around $\left(27^{\circ} \mathrm{N}, 140^{\circ} \mathrm{E}\right)$. The spatial patterns of OLR and stream function anomalies reflect those of precipitation and circulation anomalies in the TBO mode (Fig. 6b). In contrast, the OLR and stream function anomalies to the southeast of Japan are smaller in EXT than in ALL (Fig. 10b). This implies that TC activity is a prerequisite for forming the anomaly fields in ALL. In fact, in WIT (Fig. 10c), the OLR and stream function anomalies near the negative center to the southeast of Japan are larger than those in EXT. A wave train reminiscent of the PJ pattern appears in the WNP, probably caused by strong TC activity with the large ACE in Region E (Table 3). Since the location of Region E with deep convection is different from that of Region $\mathrm{A}$, the spatial phase of the wave train is shifted northeastward relative to that shown in Fig. 9c. As a result, the TC activity in Region E (Fig. 10c) and the large-scale atmospheric circulations without this effect (Fig. 10b) complement the anomaly fields in ALL for $\mathrm{TBO} / \mathrm{L}$ (Fig. 10a). In particular, the TC activity in Region $\mathrm{E}$ can give significance to the OLR anomalies to the southeast of Japan.

In ALL for TBO/E (Fig. 10d), the OLR and stream 
function anomalies yield an image with the opposite polarity to that in ALL for TBO/L (Fig. 10a). This is characterized by negative OLR anomalies that stretch from the southeastern part of China to central Japan, and positive anomalies that spread to the southeast of Japan. In addition, an anomalous anticyclone appears to the southeast of Japan near $\left(27^{\circ} \mathrm{N}, 143^{\circ} \mathrm{E}\right)$. The anomalous anticyclone may occur because of the PEAlike teleconnection, related to convection in the eastern tropical Pacific where positive SSTAs are developed. The OLR and stream function anomalies in EXT (Fig. 10e) well correspond to those in the ALL, whereas the image for WIT (Fig. 10f) is very different. Regarding total anomaly fields in ALL for TBO/E (Fig. 10d), the large-scale atmospheric circulations without TCs in Region E mainly contribute (Fig. 10e), whereas there is almost no covariation with TC activity (Fig. 10f).

Figures 9 and 10 suggest that TC activity in the WNP covaries with large-scale atmospheric circulations in ENSO/L and TBO/L. However, the TC activity may be involved in intraseasonal or biweekly oscillations. For example, the Madden-Julian oscillation (MJO), which represents an intraseasonal oscillation in the tropics, tends to increase TC genesis in the WNP in its active convection phase (Liebmann et al. 1994). To examine the covariability of TC activity in Regions A and E with those subseasonal oscillations, we performed a lagged composite analysis for OLR, stream function at $850 \mathrm{hPa}$, and vertically $(250-850 \mathrm{hPa})$ averaged temperature (Fig. 11). The vertically averaged temperature is proportional to the thickness of the entire troposphere, which is useful when evaluating warming by latent heat release from convection and cooling by southward movement of air in the mid-latitudes. If the WIT composites (Figs. 9c, 10c) are involved in subseasonal oscillations, the lagged changes of these three variables should show a subseasonal periodicity.

The result in Region A for ENSO/L (Fig. 11a) shows an anomalous cyclone, negative OLR, and positive vertically averaged temperature anomalies in the day lag 0 , indicating enhanced convection with strong TC activity. The time changes in these three variables indicate very little subseasonal tendency. Changes in OLR and vertically averaged temperature display a soliton-like variation rather than an oscillation. A favorable condition for the genesis and development of TCs seems to appear from the day lag -10 or so. This preconditioning suggests that large-scale atmospheric circulations locally induce TC activity, and there is a covariation between the large-scale atmospheric circulations and TC activity during the period. The convective activity in Region A (Fig. 9c) is mainly enhanced
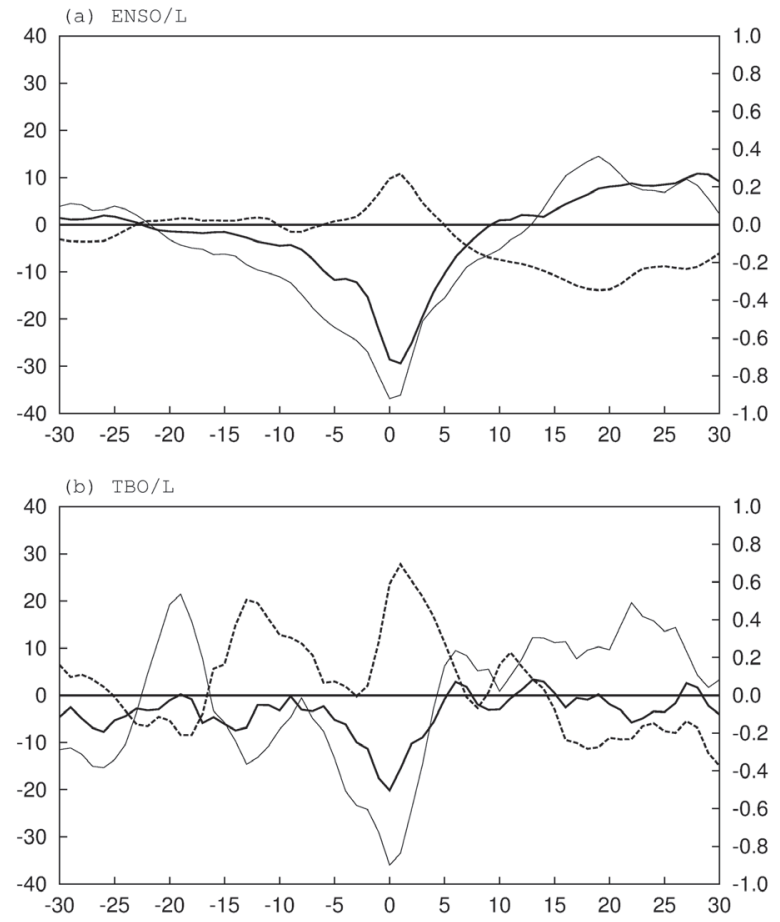

Fig. 11. (a) Lagged composite values of stream function anomalies at $850 \mathrm{hPa}\left(10^{5} \mathrm{~m}^{2} \mathrm{~s}^{-1}\right.$; thin solid line), OLR anomalies $\left(\mathrm{W} \mathrm{m}^{-2}\right.$; thick solid line), and vertically $(250-850 \mathrm{hPa})$ averaged temperature anomalies (K; dotted line) in Region A for $\mathrm{ENSO} / \mathrm{L}$. These anomalies were derived from the long-term means removing respective seasonal variations. The abscissa denotes lagged days. Day 0 means the existence of TCs in Region $\mathrm{A}$. The left ordinate shows stream function and OLR anomalies, while the right ordinate shows vertically averaged temperature anomalies. (b) As in (a), but for Region $\mathrm{E}$ for $\mathrm{TBO} / \mathrm{L}$.

by TC activity without subseasonal oscillations.

In Region E for TBO/L (Fig. 11b), an anomalous cyclone, negative OLR, and positive vertically averaged temperature anomalies are significant in the day lag 0 , which indicates enhanced convective activity connected to strong TC activity. The large variability shown in Fig. 11b may be due to the small number of counted TCs (Table 4). The three variables seem not to have systematic subseasonal oscillations. In particular, the variation in OLR anomalies is not consistent. The precondition for TCs with convective and large-scale cyclonic circulation anomalies is set from the day lag -5 , although this period is shorter than that in Region A for ENSO/L (Fig. 11a). This preconditioning again 

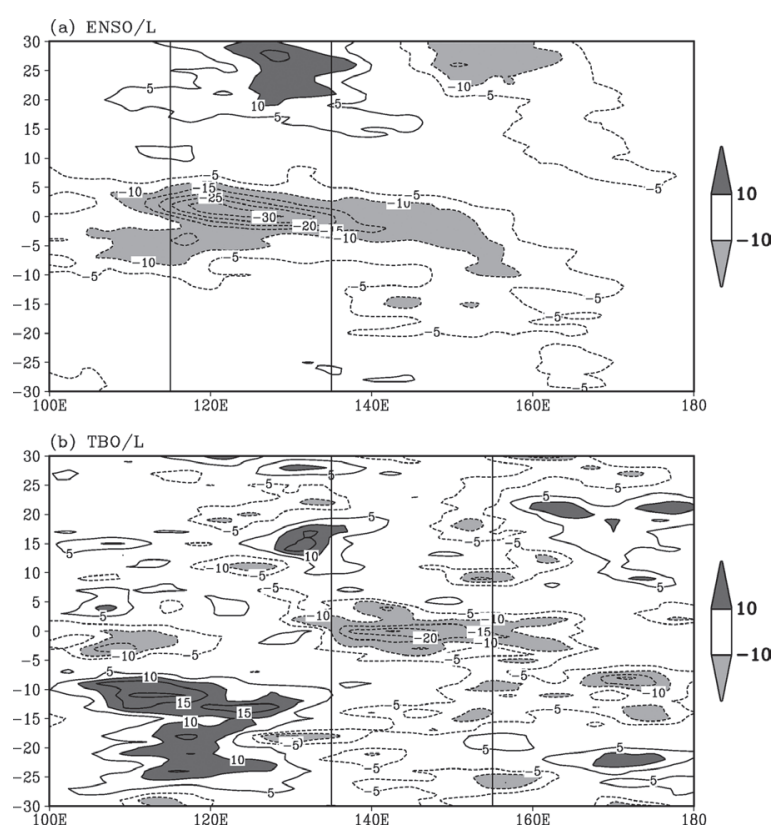

Fig. 12. Time-longitude cross sections of OLR anomalies along the latitudinal bands, (a) $12.5^{\circ}-22.5^{\circ} \mathrm{N}$ for $\mathrm{ENSO} / \mathrm{L}$ and (b) $22.5^{\circ}-32.5^{\circ} \mathrm{N}$ for $\mathrm{TBO} / \mathrm{L}$. The contour interval is $5.0 \mathrm{~W} \mathrm{~m}^{-2}$, and dotted lines denote negative values. Zero lines are omitted for clarity. The shading scale is provided to the right of each panel. The abscissa denotes longitudes, and the ordinate indicates lagged days.

suggests that there is a covariation between TC activity and large-scale atmospheric circulations. It is conceivable that convective activity in Region E (Fig. 10c) mainly collaborates with TC activity without well-organized subseasonal oscillations.

To examine the existence of subseasonal oscillations in more depth, we investigated the time-longitude cross sections of OLR anomalies with lags from -30 to 30 days corresponding to those in Fig 11 (Fig. 12). The latitudinal bands are $12.5^{\circ}-22.5^{\circ} \mathrm{N}$ for ENSO/L (Fig. $12 \mathrm{a}$ ) and $22.5^{\circ}-32.5^{\circ} \mathrm{N}$ for TBO/L (Fig. 12b). Since subseasonal oscillations excited by Rossby waves tend to move westward in the subtropics (Wang and Xie 1997), the OLR anomalies would indicate a westward movement in the latitudes if the oscillations are dominant. However, the OLR anomalies did not show such a westward movement with the subseasonal oscillations and were rather stationary in the day lag 0 in both ENSO/L (Fig. 12a) and TBO/L (Fig. 12b). In ENSO/L, the center of OLR anomalies seems to move slightly westward from $140^{\circ} \mathrm{E}$ to $110^{\circ} \mathrm{E}$ around the day lag 0 .
This westward movement stopped by $110^{\circ} \mathrm{E}$, and did not reach South Asia unlike Rossby waves. The rapid end is probably caused by the landing of TCs on the Asian continent. In TBO/L, negative OLR anomalies have a maximum between $135^{\circ} \mathrm{E}$ and $155^{\circ} \mathrm{E}$ around the day lag 0; this occurs simultaneously, without subseasonal oscillations. These results show that anomalous convection in Region A during ENSO/L and in Region E during TBO/L have weak correlation with subseasonal oscillations.

\section{Summary}

This work investigated the covariability between the Baiu precipitation and TC activity in the WNP through large-scale atmospheric circulations associated with the ENSO and the TBO of the Asian monsoon. Using 30 year data from 1979 to 2008 , this work focused on the interannual variability in precipitation of Baiu region near Japan $\left(25^{\circ}-40^{\circ} \mathrm{N}, 125^{\circ}-155^{\circ} \mathrm{E}\right)$.

To extract predominant spatiotemporal structures from the interannual variability, we applied the EOF analysis to the precipitation rates near Japan in the Baiu season (June and July) for 30 years. The EOF1 showed an interannual variation along the entire Baiu front (Fig. 3a) with a periodicity of about 5 years (Figs. $3 \mathrm{~b}, \mathrm{c}$ ), which was controlled by the ENSO (Fig. 5a). The EOF2 captured an aspect of the TBO with a dipole between Kyushu and the center to southeast of Japan (Fig. 4a), which displayed a quasi-biennial periodicity (Figs. 4b, c). This work calls these two EOF modes the ENSO and TBO modes, respectively, and confirmed that the third and higher EOF modes were not correlated with the ENSO or the TBO. This work has examined that the Baiu precipitation is modulated by both the ENSO and the TBO. For the ENSO and TBO modes, the La Niña-like and El Niño-like cases were defined using SSTAs in the eastern tropical Pacific. We termed these cases $\mathrm{ENSO} / \mathrm{L}, \mathrm{ENSO} / \mathrm{E}, \mathrm{TBO} / \mathrm{L}$, and $\mathrm{TBO} / \mathrm{E}$; where /L and /E indicates the La Niña-like and El Niño-like cases, respectively. The associated large-scale atmospheric circulations and covariability between the Baiu precipitation and TC activity in the WNP were examined for each case.

As indices of TC activity, this work employed NTC and ACE. To choose specific regions, we focused on areas where large stream function anomalies appeared (Fig. 6). In ENSO/L, NTC significantly increased around the Philippines (Table 2); while in TBO/L, ACE was significantly enhanced in the area to the southeast of Japan, around $28^{\circ} \mathrm{N}, 145^{\circ} \mathrm{E}$ (Table 3). TC activity in the two regions had a significant relationship with atmospheric circulations affecting the Baiu precipitation, 
(a) ENSO/L

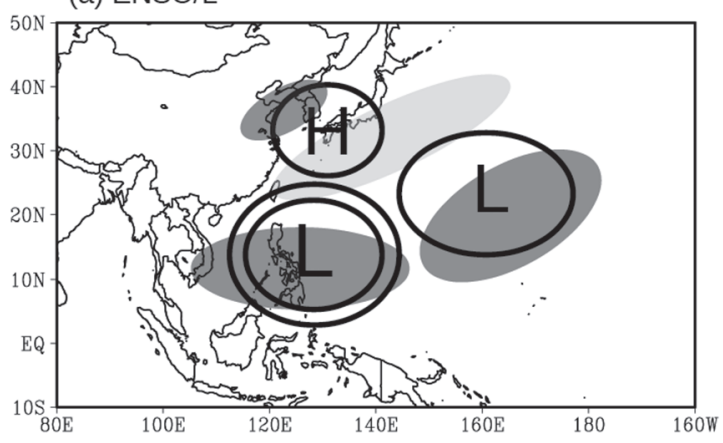

(b) $\mathrm{TBO} / \mathrm{L}$

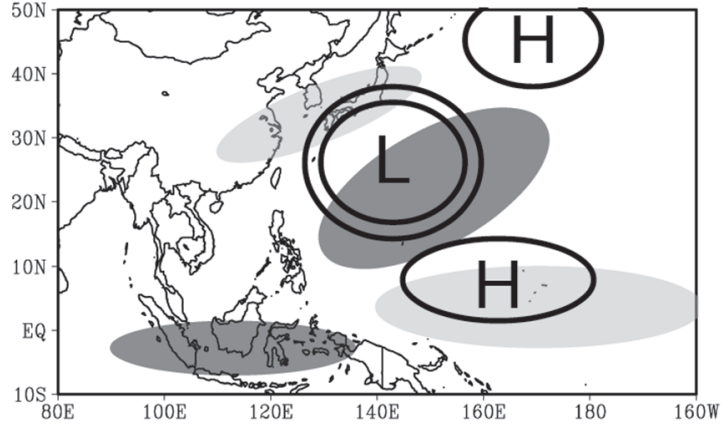

Fig. 13. Schematic diagrams of (a) ENSO/L and (b) TBO/L. Dark (light) shades mark regions with positive (negative) precipitation rate anomalies. The circle and L $(\mathrm{H})$ denote the anomalous cyclones (anticyclones). Double circles indicate the cyclonic circulations modified by TC activity.

which was also associated with the ENSO and TBO modes.

To diagnose the effects of TCs on the specified regions, this work estimated the ALL, EXT, and WIT composites using daily mean data. Both ENSO/L and $\mathrm{TBO} / \mathrm{L}$ exhibited a covariation between the Baiu precipitation and TC activity through large-scale atmospheric circulations, which is summarized in Fig. 13. For ENSO/L and TBO/L, the effects of TC activity complemented the atmospheric circulation anomalies and modified the axis of monsoon westerlies in the WNP (Figs. 9, 10), which supports formation of precipitation rate anomalies in the Baiu front (Figs. 6a, b). Without these effects, the atmospheric circulation does not form suitable anomaly fields that are related to dominant interannual modulations of Baiu precipitation in $\mathrm{ENSO} / \mathrm{L}$ and $\mathrm{TBO} / \mathrm{L}$. In addition, subseasonal oscillations were not well correlated to TC activity over the centers of atmospheric circulations (Figs. 11, 12). The effects of TC activity are unimportant in EN$\mathrm{SO} / \mathrm{E}$ and $\mathrm{TBO} / \mathrm{E}$ for the anomalous atmospheric circulations associated with the interannual modulations of Baiu precipitation. Therefore, TC activity in the WNP selectively covaries with the atmospheric circulations associated with modulations in the Baiu precipitation, according to the phases of ENSO and TBO.

The relationship between the TC activity and the large-scale atmospheric circulations may need further verification. Using data with low spatiotemporal resolution such as observational or canonical reanalysis data, the evaluation of direct and indirect effects of TCs on the Baiu precipitation would be difficult. How do we isolate the causes of interannual modulations of Baiu precipitation? How do we quantitatively estimate these direct and indirect effects? To approach these issues, sensitivity experiments with large-scale and high spatiotemporal resolution models are required. We are conducting such numerical experiments using a stateof-the-art general circulation model (GCM) which can simulate realistic TCs and the Baiu precipitation in a non-hydrostatic frame.

\section{Acknowledgments}

The authors thank two anonymous reviewers for their useful comments and constructive suggestions. This work was supported by a Grant-in-Aid for Scientific Research $(20240075,22106005)$ of the Ministry of Education, Culture, Sports, Science, and Technology (MEXT) of Japan.

\section{References}

Adler, F. R., G. J. Huffman, A. Chang, R. Ferraro, P.-P. Xie, J. Janowiak, B. Rudolf, U. Schneider, S. Curtis, D. Blvin, A. Gruber, J. Susskind, P. Arkin, and E. Nelkin, 2003: The version-2 global precipitation climatology project (GPCP) monthly precipitation analysis (1979-present). Journal of Hydrometeorology, 4, 1147-1167.

Bell, G. D., M. S. Halpert, R. C. Schnell, R. W. Higgins, J. Lawrimore, V. E. Kousky, R. Tinker, W. Thiaw, M. Chelliah, and A. Artusa, 2000: Climate assessment for 1999. Bull. Amer. Meteor. Soc., 81, S1-S50

Camargo, S. J., and A. H. Sobel, 2005: Western North Pacific tropical cyclone intensity and ENSO. J. Climate, 18, 2996-3006.

Chan, J. C. L., 2000: Tropical cyclone activity over the western North Pacific associated with El Niño and La Niña events. J. Climate, 13, 2960-2972.

Chan, J. C. L., 2007: Interannual variations of intense typhoon activity. Tellus, 59A, 455-460. 
Chang, C.-P., and T. Li 2000: A theory for the Tropospheric Biennial Oscillation. J. Climate, 57, 2209-2224.

Chang, C.-P., Y. Zhang, and T. Li, 2000a: Interannual and interdecadal variations of the East Asian summer monsoon and tropical Pacific SSTs. Part I: Roles of the subtropical ridge. J. Climate, 13, 4310-4325.

Chang, C.-P., Y. Zhang, and T. Li, 2000b: Interannual and interdecadal variations of the East Asian summer monsoon and tropical Pacific SSTs. Part II: Meridional structure of the monsoon. J. Climate, 13, 4326-4340.

Kawamura, R., and T. Murakami, 1998: Baiu near Japan and its relation to summer monsoons over Southeast Asia and the Western Pacific. J. Meteor. Soc. Japan, 76, 619-639.

Kawamura, R., and T. Ogasawara, 2006: On the role of typhoons in generating PJ teleconnection patterns over the western North Pacific in late summer. SOLA., 2, 37-40.

Kawamura, R., T. Matsuura, and S. Iizuka, 2003: Equatorially symmetric impact of the El Niño-Southern Oscillation on the South Asian summer monsoon system. $J$. Meteor. Soc. Japan, 81, 1329-1352.

Lau, K.-M., and H. T. Wu, 2001: Principal mode of rainfall-SST variability of the Asian summer monsoon: A reassessment of the monsoon-ENSO relationship. $J$. Climate, 14, 2880-2895.

Li, T., P. Liu, X. Fu, and B. Wang, 2006: Spatiotemporal structures and mechanisms of the Tropospheric Biennial Oscillation in the Indo-Pacific warm ocean regions. J. Climate, 19, 3070-3086.

Liebmann, B., and C. A. Smith, 1996: Description of a complete (interpolated) OLR dataset. Bull. Amer. Meteor. Soc., 77, 1275-1277.

Liebmann, B., H. H. Hendon, and J. D. Glick, 1994: The relationship between tropical cyclones of the western Pacific and Indian Oceans and the Madden-Julian Oscillation. J. Meteor. Soc. Japan, 72, 401-412.

Meehl, G. A., 1987: The annual cycle and interannual variability in the tropical Pacific and Indian Ocean regions. Mon. Wea. Rev., 115, 27-50.

Meehl, G. A., 1993: A coupled air-sea biennial mechanism in the tropical Indian and Pacific regions: Role of the ocean. J. Climate, 6, 31-41.

Meehl, G. A. 1997: The South Asian monsoon and the tropospheric biennial oscillation. J. Climate, 10, 1921-1943.

Meehl, G. A., and J. M. Arblaster, 2002: The tropospheric biennial oscillation and Asian-Australian monsoon rainfall. J. Climate, 15, 722-744.

Meehl, G. A., J. M. Arblaster, and J. Loschnigg, 2003: Coupled ocean-atmosphere dynamical processes in the tropical Indian and Pacific Ocean regions and the TBO. J. Climate, 16, 2138-2158.

Onogi, K., J. Tsutsui, H. Koide, M. Sakamoto, S. Kobayashi, H. Hatsushika, T. Matsumoto, N. Yamazaki, H. Kamahori, K. Takahashi, S. Kadokura, K. Wada, K. Kato, R. Oyama, T. Ose, N. Mannoji, and R. Taira, 2007:
The JRA-25 reanalysis. J. Meteor. Soc. Japan, 85, 369-432.

Press, W. H., S. A. Teukolsky, W. T. Vetterling, and B. P. Flannery, 1992: Numerical Recipes in FORTRAN 2nd Edition: The art of scientific computing. Cambridge University Press, 611-612.

Rasmusson, E. M., and T. H. Carpenter, 1982: Variations in tropical sea surface temperature and surface wind fields associated with the Southern Oscillation/El Niño. Mon. Wea. Rev., 110, 354-384.

Rayner, N. A., D. E. Parker, E. B. Horton, C. K. Folland, L. V. Alexander, D. P. Rowell, E. C. Kent, and A. Kaplan, 2003: Global analyses of sea surface temperature, sea ice, and night marine air temperature since the late nineteenth century. J. Geophys. Res., 108, No. D14, 4407 10.1029/2002JD002670.

Shen, S., and K-M. Lau, 1995: Biennial oscillation associated with the East Asian summer monsoon and tropical monsoon and tropical sea surface temperature. J. Meteor. Soc. Japan 73: 105-124.

Takaya, K., and H. Nakamura, 2001: A formulation of a phase-independent wave-activity flux for stationary and migratory quasigeostrophic eddies on a zonally varying basic flow. J. Atmos. Sci., 58, 608-627.

Tanaka, M., 1997: Interannual and interdecadal variations of the western North Pacific monsoon and Baiu rainfall and their relationship to the ENSO cycles. J. Meteor. Soc. Japan, 75, 1109-1123.

Tomita, T., and T. Yasunari, 1996: Role of the northeast winter monsoon on the biennial oscillation of the ENSO/ monsoon system. J. Meteor. Soc. Japan, 74, 399-413.

Tomita, T., T. Yoshitake, and T. Yasunari, 2004: Biennial and lower-frequency variability observed in the early summer climate in the western North Pacific. J. Climate, 17, 4254-4266.

Wang, B., and J. C. L. Chan, 2002: How strong ENSO events affect tropical storm activity over the western North Pacific. J. Climate, 15, 1643-1658.

Wang, B., and X. Xie, 1997: A model for the boreal summer intraseasonal oscillation. J. Atmos. Sci., 54, 72-86.

Wang, B., R. Wu, and X. Fu, 2000: Pacific-East Asian teleconnection: How does ENSO affect East Asian climate? J. Climate, 13, 1517-1536.

Xie, S.-P., K. Hu, J. Hafner, H. Tokinaga, Y. Du, G. Huang, and T. Sampe, 2009: Indian Ocean capacitor effect on Indo-Western Pacific climate during the summer following El Niño. J. Climate, 22, 730-747.

Yamada, K., and R. Kawamura, 2007: Dynamical link between typhoon activity and the PJ teleconnection pattern from early summer to autumn as revealed by the JRA-25 reanalysis. SOLA., 3, 65-68.

Yamaura, T., and T. Tomita, 2011: Spatiotemporal differences in the interannual variability of Baiu frontal activity in June: Int. J. Climatol., 31, 57-71, doi:10.1002/ joc. 2058 . 